\title{
Field Model Simulations of Vehicle Fires in a Channel Tunnel Shuttle Wagon
}

\author{
S. KUMAR \\ Fire Research Station \\ Borehamwood, Herts WD6 2BL, UK
}

\section{ABSTRACT}

The field model JASMINE has been adapted to simulate the environmental conditions resulting from a vehicle fire that may occur in a channel tunnel shuttle wagon in transit. The calibration and verification of the model against a full scale car fire test initiated with seat ignition are then presented. An interesting feature of the modelling study was to simulate the interaction of the flows generated due to the fire with those due to the complex ventilation system of the shuttle wagon. It has been demonstrated that the model can reproduce satisfactorily both the thermal and chemical characteristics as observed in the test. The correspondence depends on selection of a realistic prescription for the fire growth curve and the ventilation system and by assuming that heat losses to the wagon walls and ceiling are properly acounted for.

KEYWORDS: Mathematical field model, Channel tunnel shuttle wagon, Cerchar tests, Cardington car tests, Car fire, Seat fire, Ventilation system, Model verification

\section{INTRODUCTION}

The tourist shuttle trains to be used in the $50 \mathrm{~km}$ long channel tunnel have been designed on the basis of car passengers travelling with their vehicles within the shuttle wagons.

In order to provide information on which the design of an optimal fire detection and extinguishment system could be based full scale fire tests were performed at the INERIS laboratories formerly known as CERCHAR (Centre d'Etudes et Recherches de Charbonages) in Northern France over the period 1987-1991. The final series of the tests were conducted in a fully representative double decker shuttle wagon to cover several possible types of incident resulting from a car fire. Within the lower deck of the wagon the walls, the ceiling, the interior arrangement of the floor drainage system, the ventilation system and the fire detection and extinguishment system(FDE) were fully represented. The FDE system includes ionisation and optical detectors as well as a halon extinguishing system discharging at ceiling level. The main objective of the tests was to demonstrate that, in 
the event of a fire within a shuttle wagon, automatic detection of a potential safety hazard occurs and, if the situation develops to serious proportions, automatic discharge of halon fire extinguishment occurs.

Because of their high cost, the full scale tests have been complemented with the data from fire modelling study so that other particular scenarios of interest could be studied. The purpose of this study was to investigate what would happen in the event of a car fire taking place in one of the shuttle wagons for a number of different scenarios.

In this paper a description is given of the field model JASHINE adapted to simulate the environmental conditions resulting from a vehicle fire that may occur in a channel tunnel shuttle wagon in transit. The model set-up describes the internal geometry of the wagon, the complex ventilation system comprising six ventilation grills on each side wall of the wagon and the internal geometry of the 'car-on-fire' where fire initiated by seat ignition was allowed to spread horizontally. An interesting feature of the modelling study was to simulate the interaction of the flows generated due to the fire with those due to the complex ventilation system of the shuttle wagon. The prefire steady state convection flow due to the ventilation system alone is first simulated and is then used as the initial condition imposed on the flow after the fire was ignited. The calibration and verification of the model against a full scale car fire test initiated with seat ignition within a mockup of the shuttle wagon configuration are then presented.

\section{HODEL DESCRIPTION}

The model JASMINE analyses smoke transport inside an enclosure by exploiting the techniques of Computational Fluid Dynamics(CFD) to solve the governing equations of conservation of mass, momentum, heat and chemical species locally at several thousand elementary control volumes (also known as numerical grid cells) within the enclosure. It incorporates the important transport processes and their interactions relevant to the movement of smoke. The key processes are buoyancy, convection, entrainment, turbulence, combustion, thermal radiation, and heat transfer to the enclosure boundaries. The detalled mathematical description of JASMINE and the sub-models it utilises can be found in Refs 1-5. The assumptions and limitations of its use in this application are as follows.

Turbulent processes in fires were modelled by a standard $\mathbf{k}-\varepsilon$ sub-model, where $k$ is the turbulent kinetic energy of the flow and $\varepsilon$ is its rate of dissipation. The effects of buoyancy on production and dissipation of turbulence were included. Combustion processes in fires were modelled by a modified eddy break up sub-model where the rate of reaction is controlled by the slow turbulent mixing of fuel volatiles and air and not by the fast reaction kinetics. The turbulent boundary layer adjacent to the enclosure walls was modelled by a standard 'wall function' approach. Heat transfer (including radiation) to the enclosure walls was modelled by a local lumped heat transfer coefficient $[1,2]$. The local heat transfer coefficient was allowed to vary linearly between $5 \mathrm{~W} / \mathrm{m}^{2} /{ }^{\circ} \mathrm{C}$ and $40 \mathrm{~W} / \mathrm{m}^{2} /{ }^{\circ} \mathrm{C}$ for a gas temperature between ambient and $100^{\circ} \mathrm{C}$ rise above ambient adjacent to walls. For gas temperature rise above $100^{\circ} \mathrm{C}$ this was set to 40 $\nabla / \mathrm{m}^{2} /{ }^{\circ} \mathrm{C}$. A first order 'upwind' differencing scheme was used for the numerical discretisation of the partial differential equations describing the conservation of mass, momentum, heat and chemical species. 
The current state of development of fire science does not allow a reliable prediction, from first principles, of the rate of fire growth. Without measurement of particular rate-of-heat-release histories, it is not possible to predict precisely the consequences of individual fires. Thus in the present study the fire growth rate was taken from measurements obtained in full scale experimental tests carried out at Cardington [6] using motor vehicles similar to those used in the CERCHAR tests.

\section{HODEL SETUP}

The geometry under consideration as shown in Fig 1 was the full scale mock-up, representing the main vagon together with quarter sections of the adjacent wagons of a three wagon configuration of the channel tunnel shuttle, as used for the CERCHAR tests. The main wagon was $24.58 \mathrm{~m}$ in length, $3.75 \mathrm{~m}$ in width, and its lower deck $2.11 \mathrm{~m}$ in height. The lower deck included four cars where the 'car-on-fire' was at the rear end of the wagon. For practical reasons there was an empty space within the mockup where the centrally located fifth car would normally be located.

Only the lower deck of the mockup was modelled since in the experimental test series the door to the upper deck was closed. A Cartesian co-ordinate system was used throughout. The main features as incorporated in the model set-up are as follows:

Ventilation System. Each wagon has a ventilation system designed to provide a comfortable atmosphere under normal operating conditions and can be used to dilute any noxious gases that may be detected. To achieve smoke containment the system includes dampers which are closed if a fire is detected or there is a power failure. The system consisted of six ventilation grills situated on each side wall of the vagon and was connected to its upper deck through external pipe network. The orientation of the grill inlets $\left(30^{\circ}\right.$ with respect to the horizontal) and the variable inflow rates thorough the ventilation grills give rise to complex convection flow patterns inside the wagon. For convenience, the flow through between-deck ventilation pipe network was not simulated. The flow through the ventilation grill openings can, however, be used to give some indication of the smoke leakage into the ventilation network.

To ensure a realistic simulation of the inflow and outflow through the ventilation grills, the calculation domain was extended to create a plenum outside the grills and on both sides of the mockup (see Fig 1). The inflow and outflow in the plenum were separated by a horizontal divider. A grill inlet was then defined by fixing the prescribed inflow rate for each grill at the domain boundary, and the horizontal and vertical components of the inflow velocity at the inlet location. The volume flow rates through the grills are given in Table 1 . For the grill outlet a fixed outflow boundary condition was defined at the domain boundary.

The ventilation system was shut down when the fire was confirmed by any two detectors in the wagon. During its shut-down the effect of the inertia of the fan in the ventilation system was also examined.

Car-on-fire. The 'car-on-fire' was represented by a simplified geometry. Some of the internal geometry of the 'car-on-fire' was included. A simplified representation of the its seats was used. Special attention was paid to the window openings as these determine the rate of air supply to the fire inside the car. 


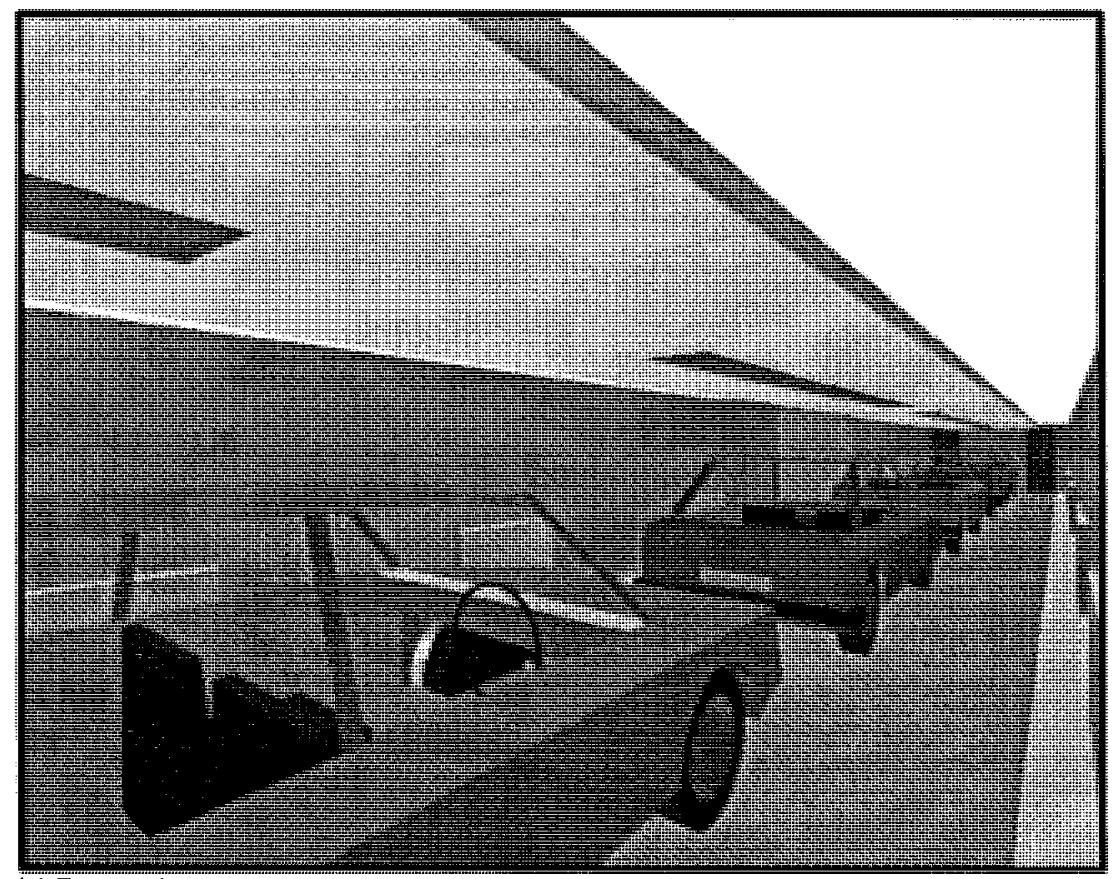

(a) Perspective view
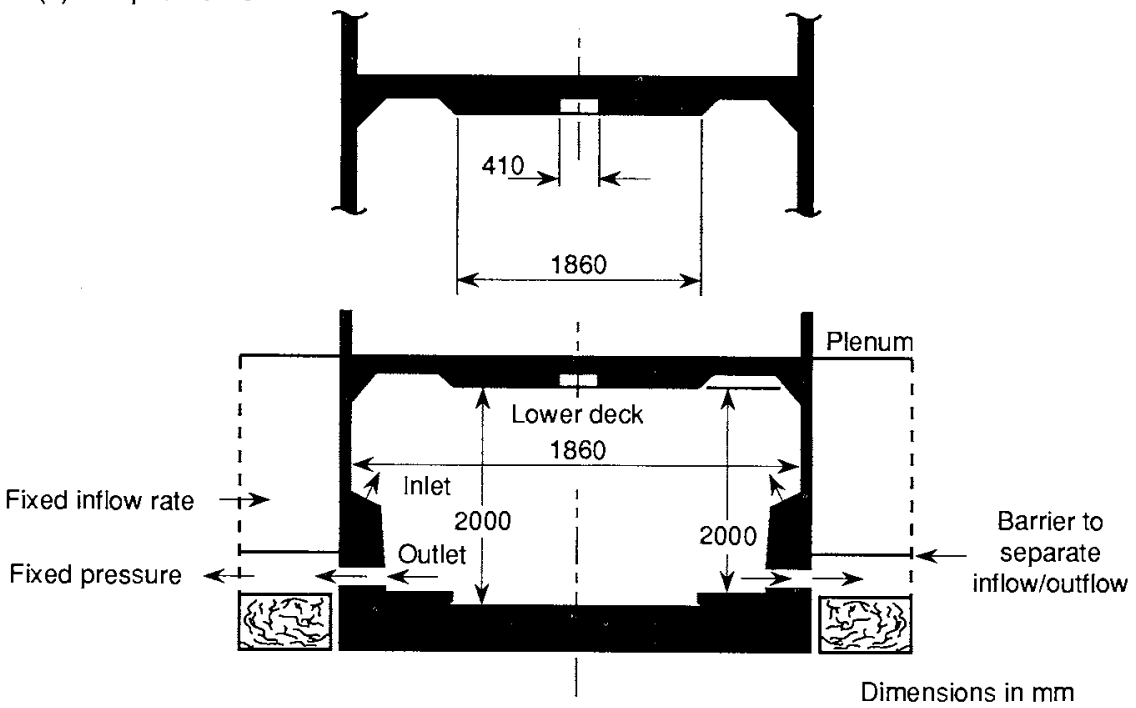

(b) Transverse section through a pair of ventilation grills

FIGURE 1 Schematic of a wagon interior 


$\begin{array}{lll}\text { Grills* } & \text { 'South' side wall } & \text { 'North' side wall } \\ \text { (opposite to staircase) } & \text { (along staircase) }\end{array}$

\begin{tabular}{lll}
\hline & 358 & 348 \\
1 & 507 & 459 \\
2 & 618 & 635 \\
3 & 745 & 510 \\
4 & 492 & 584 \\
5 & 439 & 427 \\
6 & & \\
\hline
\end{tabular}

* grill pair 1 is adjacent to 'car-on-fire'

Other Cars. Other cars were included simply as obstructions to the flow. Ceiling Detector Recesses. The detector recesses in the false ceiling of the wagon, as shown in Fig 1 , was simulated by using non-zero area porosities to match the numerical areas with those of the actual recesses. Central Staircase. The staircase situated centrally adjacent to a side wall of the wagon, which affects the lateral as well as longitudinal smoke spread close to the 'car-on-fire', was included as obstruction to the flow. Spreading Fire Source. The fire was initiated with the ignition of a no. 7 crib as specified in British Standard BS 5852 and was then allowed to spread over the entire seating area of the car. The fire growth curve representing the early transient development of the fire source was obtained from the calorimetry data acquired at Borehamwoood on individual car seats and the full scale car fire tests carried out at Cardington [6]. Heat Transfer to Boundaries. The walls and ceiling of the wagon were made up of $1.5 \mathrm{~mm}$ thick steel sheet which were covered on the outside with rock wool insulation. The false ceiling containing the recess for detectors was made up of $3 \mathrm{~mm}$ melamine laminate. The heat losses to the steel body and the false ceiling, which would depend on its large surface area and its transient heating conditions, were incorporated using the lumped heat transfer coefficient approach described earlier.

Numerical Grid. A non-uniform numerical grid with a finer resolution close to the car-on-fire was used. A total of $14040 \mathrm{grid}$ cells was used for this lower deck of the mock-up. 576 of the $14040 \mathrm{grid}$ cells represented the 'car-on-fire' and a total of 1080 grid cells were used for each plenum outside the ventilation grills (ie the extended domain outside the mock-up).

\section{HODEL CALIBRATION AKD VERIFICATION}

In order to check that the assumptions built into the model gave a reasonable representation of the conditions in a wagon during a fire the model was compared against a full scale 'seat fire' test which involved a fire initiated on the front seat of a car within the wagon. The test was chosen because of its severity in its rate of fire growth indicative of the "flashover" inside the car near the end of the experiment. 
In the seat fire test used to calibrate and validate the model, all four windows of the car were left fully open. The front seat of the car was slashed and was ignited by a standard wood crib. Since the standard wood crib alone contributes some $5 \mathrm{~kW}$ to the fire output, which is comparable to the heat output of the seat in its early stages, one vould expect the fire behaviour of the crib to greatly influence the early fire growth phase.

Initially the growth rate of the fire is the same as that of a free burn seat fire test. However, when the flames are long enough to extend beneath the ceiling of the car its flammable lining and the other car seats become involved contributing to the fire growth process. This gives rise to a rapid fire development leading to a "flashover" inside the car as was observed in the full scale tests conducted at Cardington [6]. The transient growth rate of the fire inside the car was not measured. The measured fire growth rates from the individual seat and complete car fire tests are compared in Fig 2. It should be noted that the fire growth behaviour in the Cardington and CERCHAR fire tests may not be identical because of some differences in the initial and local ventilation conditions which include extent of seat slashing, the ambient temperature, moisture contents of the fuel and window openings of the car-on-fire.

The test provided detailed measurements of gas temperatures, gas concentrations and optical densities at ceiling and 'nose' height (ie $1.5 \mathrm{~m}$ from the walkway floor which is $65 \mathrm{~mm}$ higher than the actual wagon floor) locations along the length of the mock-up. In addition, columns of thermocouples and gas sampling measurements for carbon dioxide and cabon monoxide vere also placed at the ceiling above the first three cars in the proximity of the fire. These measurement locations are shown in Fig 3.

For the experimental programme, three critical levels of fire detection were defined. A first level, denoted by $N_{1}$, was reached when the fire vas detected by any one detector and a second level denoted by $\mathrm{N}_{2}$, was reached when this was confirmed by a second detector of a different type. A third level, denoted by $\mathrm{N}_{3}$ was achieved when a $70 \%$ opacity (or optical densities per metre of $0.5 \mathrm{~m}^{-1}$ ) was achieved at any optical detector. It is this third level which was used to determine when the halon extinguishment system would activate. The fire was extinguished when halon was discharged shortly after $\mathrm{N}_{3}$ has been achieved.

In the seat fire test, the level $N_{1}$ was reached at $80 \mathrm{~s}$, the level $N_{2}$ at $160 \mathrm{~s}$ (when the ventilation system was shut down) and the level $N_{3}$ at $180 \mathrm{~s}$.

\section{Numerical Simulations}

The steady state convection flows resulting from the vagon ventilation system were first computed, which were then used as initial condition for simulation of the car fire test initiated with seat ignition. A rate of heat release curve used for this simulation comprised two phases: an early slow growth phase associated with fire confined mainly to the seat first ignited and a second rapid growth phase associated with the increasing involvement of the ceiling lining and the other seats of the car. It was clear from inspection of the Cardington full scale tests [Ref 6] that the level $\mathrm{N}_{2}$ was likely to be reached during the slow growth phase. Since the measurement of heat release rate in the Cardington tests [6] was not sufficiently accurate in these early stages data for the first phase was 


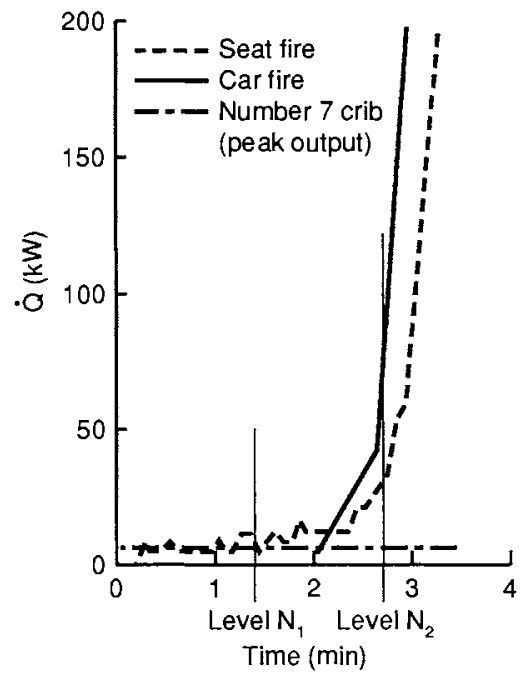

(a) Early growth plase (comparison of a seat fire in open with that of a car fire initiated with seat ignition)

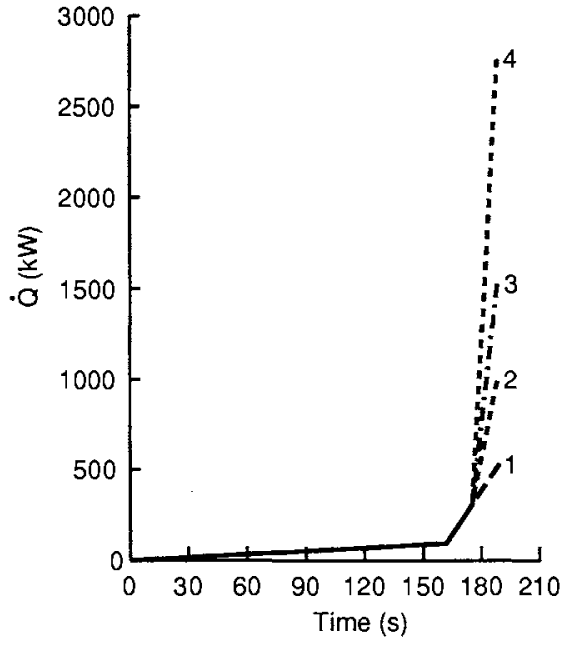

(b) Growth curves (assumptions after 160s)

FIGURE 2 Fire growth curves as used for various simulations

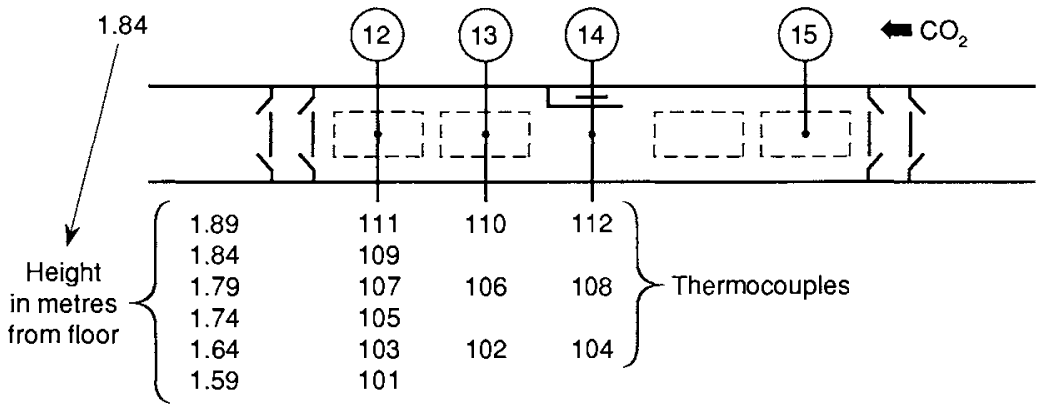

(a) Close to ceiling

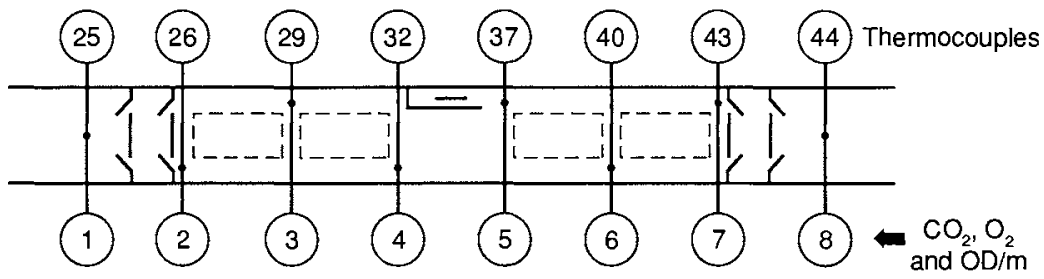

(b) At nose level (1.5m from walkway floor)

FIGURE 3 Measurement locations along the mock-up 
obtained by making further measurements at Borehamwood with a single car seat of the type used in Cardington and in the CERCHAR test. Furthermore, since the rapid growth phase of the Cardington tests were not completely representative of the CERCHAR test because of differences in the ambient temperature and ventilation between the two tests some sensitivity analysis on this second growth phase were conducted with the numerical model where the various simulations are summarised in Table 2.

The fire growth curves as used by these simulations are shown in Fig 2. The parameters varied were the slope of the growth rate curve for the steep growth phase, heat losses to the mock-up walls and ceiling and the prescription of the ventilation shut-down after level $\mathbf{N}_{2}$. An instantaneous shut-down of the ventilation was first employed in the simulation. However, to simulate the inertia of the fan in the ventilation network a more gradual shut-down was then considered where it was assumed that the flow rates were instantenously halved at level $\mathrm{N}_{2}$ and were then reduced gradually to zero in the next 20 s. All numerical simulations vere conducted until 185s.

TABLE 2. Key to symbols used in Figs 2 and 4-6

\begin{tabular}{|c|c|c|c|c|}
\hline $\begin{array}{l}\text { Numerical } \\
\text { Simulation }\end{array}$ & $\begin{array}{l}\text { (Fire Growth Curve* } \\
\text { after } \mathrm{N}_{2} \text {, Peak } \\
\text { Heat Output(KW)) }\end{array}$ & $\begin{array}{l}\text { Heat Losses } \\
\text { to Boundaries }\end{array}$ & $\begin{array}{l}\text { Ventilation }{ }^{+} \\
\text {after } \mathbf{N}_{2}\end{array}$ & Symbols \\
\hline $\begin{array}{l}1 \\
2 \\
3 \\
4 \\
5\end{array}$ & $\begin{array}{l}(1,0.330) \\
(2,1.440) \\
(3,0.952) \\
(4,2.689) \\
(2,1.440)\end{array}$ & $\begin{array}{l}\text { no } \\
\text { no } \\
\text { no } \\
\text { yes } \\
\text { yes }\end{array}$ & $\begin{array}{l}\text { off } \\
\text { off } \\
\text { off } \\
\text { off } \\
\text { gradual } \\
\text { reduction }\end{array}$ & $\begin{array}{c}--\cdots-- \\
\cdots \\
\cdots \\
\cdots\end{array}$ \\
\hline
\end{tabular}

Measurement

* same for all simulations before $\mathrm{N}_{2}(160 \mathrm{~s})$

+ ventilation on for all simulations before $N_{2}$

\section{Comparison of Predictions vith Experiment}

Figs 4 and 5 compare the evolution of the JASMINE predictions with measurements at ceiling and 'nose' height locations along the length of the mockup. Here the measurements are denoted by circles and the predictions are marked 1 to 5 for the five numerical simulations ( see also Table 2 for key to various symbols). For simulation 1 which represents a fire growth rate similar to the Cardington car fire tests, it is evident that the gas temperature and $\mathrm{CO}_{2}$ predictions are much lower than than those measured. This clearly suggests that the fire development in the CERCHAR test may have been more rapid than in Cardington test. It can also be seen that with increasing the rate of fire growth for the first three simulations the predictions for the $\mathrm{CO}_{2}$ concentrations moved closer to, but were still lower than, the measurements. On the other hand the gas temperature predictions were in a better agreement with the data for simulation 3 with the slightly lower fire growth rate. The reason for this discrepancy was attributed to heat being lost to the mockup boundaries which was not 


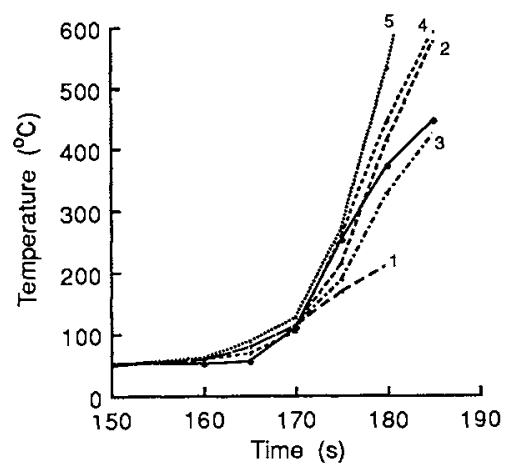

(a) Location 111

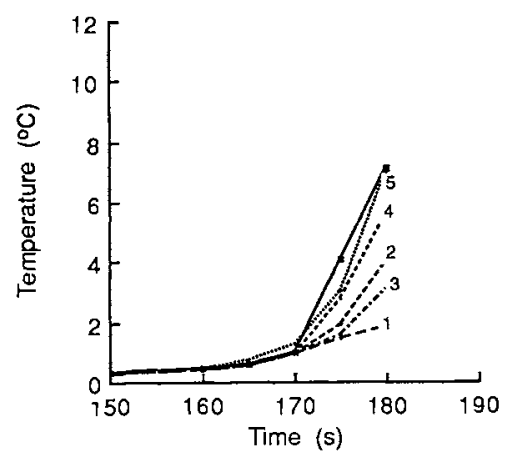

(c) Location 12

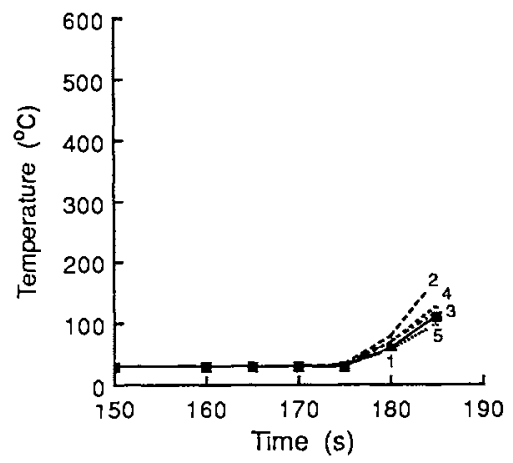

(b) Location 112

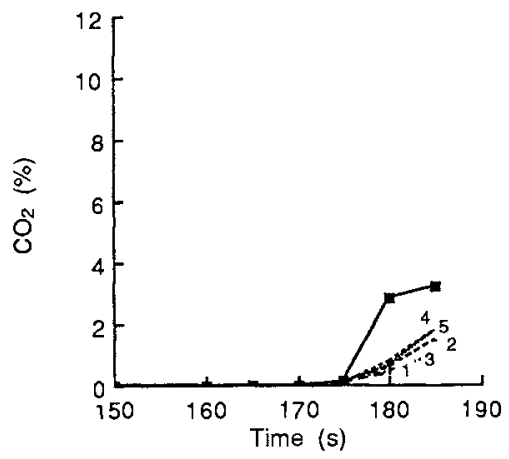

(d) Location 14

FIGURE 4 Comparison of predicted gas temperatures and $\mathrm{CO}_{2}$ concentrations with measurements at ceiling locations along the mock-up

accounted for in these simulations. However, by next increasing the rate of fire growth and by allowing heat losses to boundaries in simulation 4 , the agreement for both the ceiling gas temperatures and $\mathrm{CO}_{2}$ concentrations improved throughout except for the $\mathrm{CO}_{2}$ concentrations at location 14 . The predictions at the 'nose' height locations were, however, still in poor agreement with measurements as can be seen from Fig 5 .

The reason for the poor predictions at 'nose' height locations was traced back to the prescription of ventilation system after shut-down at level $\mathrm{N}_{2}$ where in the simulation all grill outlets vere assumed to be left open to ambient until the end of the numerical simulation. An alternative simulation 5 was therefore conducted where the more gradual ventilation shut-down described above after achievement of level $\mathrm{N}_{2}$. With these modifications the improvement in ceiling level predictions can be seen in Fig 4 and in the 'nose' height predictions in Fig 5. The predicted vertical profiles of gas temperatures along the length of the walkways as shown in Fig 6 near the end of simulation 5 (180s) are also now in satisfactory agreement with the measurements. It can be seen from Fig $5 c$ that the model has overpredicted the layer depth downstream of the fire by about $0.2 \mathrm{~m}$. 


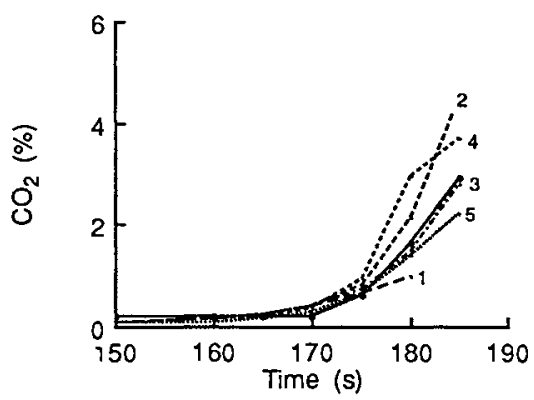

(a) Location $3^{*}$

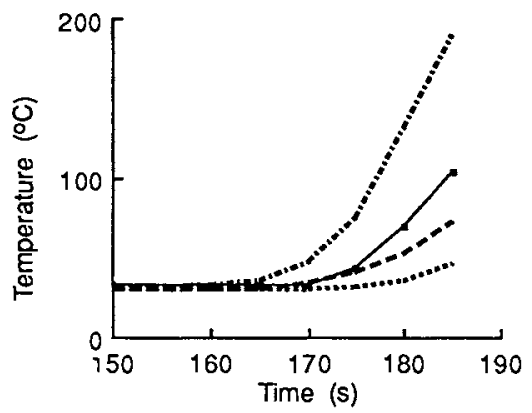

(c) Location 29, at various heights from wagon floor

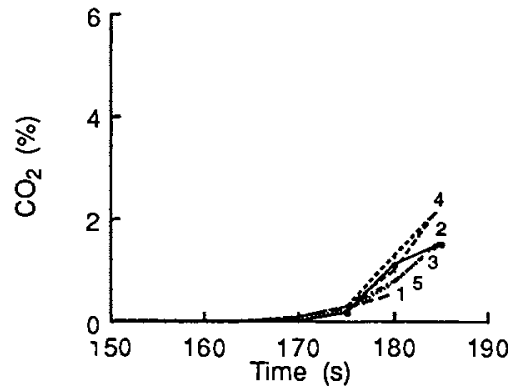

(b) Location $4^{*}$

'see Table 2 for key to symbols

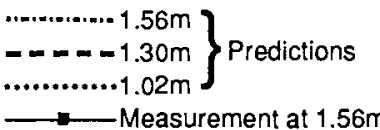

FIGURE 5 Comparison of predicted gas temperatures and $\mathrm{CO}_{2}$ concentrations with measurements at "nose" height locations along the mock-up

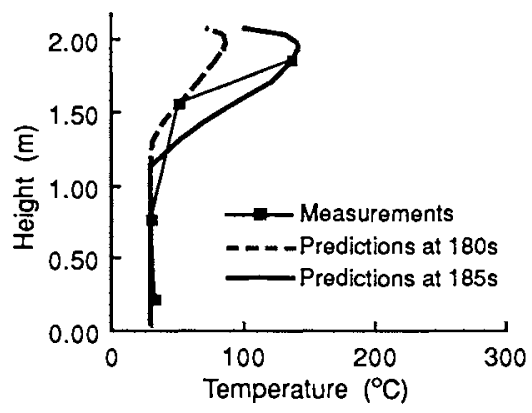

(a) Location B

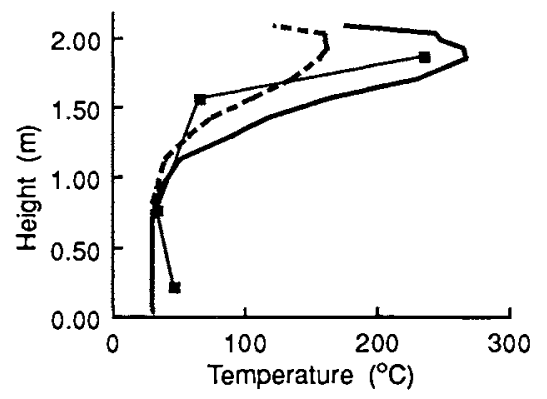

(b) Location C

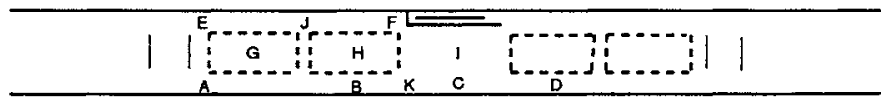

- Vehicle under $G$ is on fire

FIGURE 6 Comparison of the predicted vertical gas temperature profiles with measurements (peak values) along the mock-up 
The discrepancy in $\mathrm{CO}_{2}$ predictions and measurements at location 14 can be explained by analysing the experimental data. In well ventilated fires, one might expect a simple correlation between $\mathrm{CO}_{2}$ concentration and gas

temperature rise above ambient. For an enclosure with no heat losses to its boundaries, theoretically the correlation should be straight line passing through the origin and at $45^{\circ}$ to the coordinate axes. The measurements for the gas temperature rise against the $\mathrm{CO}_{2}$ concentration are plotted in Fig 7 which also shows a line representing the best fit to the data. Those measurements, which deviate from the line, may be questionable. The linear correlation of the data suggests for location 14 the values for $\mathrm{CO}_{2}$ at $180 \mathrm{~s}$ to be some $1.4 \%$ as compared to $2.85 \%$ measured and at $185 \mathrm{~s}$ to be some $2.6 \%$ as compared to $3.2 \%$ measured. Other data points which do not lie close to the line correspond to nose level $\mathrm{CO}_{2}$ concentrations at $180 \mathrm{~s}$ and $185 \mathrm{~s}$ for location 2 or nose level gas temperatures at 180 s and 185 s for location 26, and this also explains for somewhat poor agreement between the predictions and the measurements at these locations (not shown).

An empirical expression determined from comparison of the predicted mass fractions of combustion products $\left(m_{p r}\right)$ and measured optical densities in the CERCHAR test is:

optical density per metre $=C_{o p} \times m_{p r}\left(m^{-1}\right)$

where $C_{o p}$ is a constant of proportionality which depends on the nature of the fuel, and was equal to 35.7 for polyurethane foam assumed here to be the major component of the car seats. The evolution of the estimated optical density per metre based on the above correlation has been compared with measurements in Fig 8 where the agreement can be seen to be satisfactory. It must be emphasised here that since the optical density measurements were available only after $165 \mathrm{~s}$, it was not possible to check the validity of the above correlation for the early growth phase.

Moderate grid refinement studies were conducted only in the vertical direction. An increase in the discretisation of the vertical dimension from 18 to 25 (a total of 19500 instead of 14040 grid cells) showed little effect.

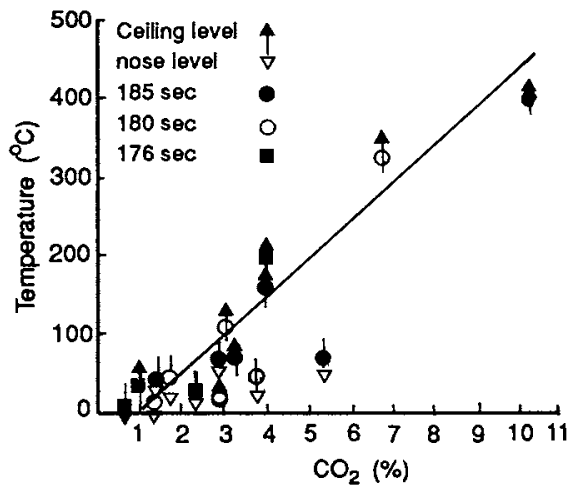

FIGURE 7 Experimental data correlation for temperature rise versus carbon dioxide concentrations

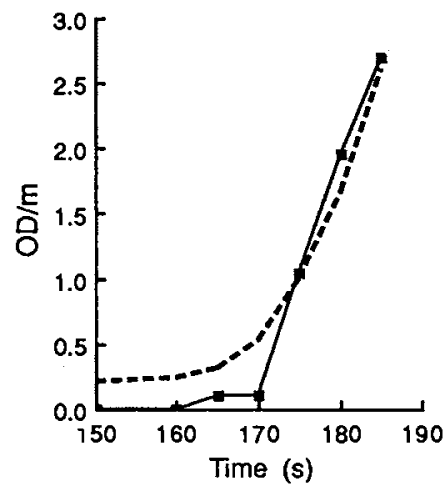

FIGURE 8 Comparisons of estimated $\mathrm{OD} / \mathrm{m}$ with measurements at Location 2 


\section{CONCLUSIONS}

It has been shown that the JASMINE model can reproduce satisfactorily both the thermal and chemical characteristics as observed in the full scale CERCHAR test. In view of the complex nature of the experimental set-up, the model appears satisfactory in its predictions of the evolution of the gas temperatures and carbon dioxide concentrations, and in the stratification of the hot layer. Some differences in the model and the experiment can be considered to be within the limits of the accuracy of the measurements. As expected, the performance of the model depends on selecting a realistic prescription of the fire growth curve and the ventilation system. The results of the thermal field predictions for the simulations 2 and 5 indicated that the heat losses to mockup walls and ceiling were important during the rapid growth phase after level $\mathrm{N}_{2}$.

Assuming that representative fire growth curves can be defined for the other scenarios, the model may then be used to give an indication of the likely fire hazard within the wagon for these scenarios.

\section{ACKNOTLEDGRHENTS}

The author acknowledges helpful discussions with $\mathrm{Mr}$ I Millman and Mr H Montalva of Eurotunnel and is greatly indebted to Professor G Cox and Dr $\mathrm{J}$ Burdett for their valuable comments and suggestions. The author is also grateful to $\mathrm{Mr}$ R Chitty and $\mathrm{Mr} \mathrm{D}$ Snell for their assistance in preparation of the figures for the paper.

The work described in this paper forms part of a contract from Eurotunnel and is contributed by the permission of the Eurotunnel, the Channel Tunnel Group Limited.

- Crown copyright 1994

\section{REFERENCES}

1. Kumar, S. and Cox, G., 'Mathematical modelling of fire in road tunnels'. In proc. 5th International Symposium on the Aerodynamics and Ventilation of Vehicle Tunnels, BHRA (1985), p.61.

2. Kumar, S, and Cox, G., 'Mathematical modelling of fire in road tunnels - validation of JASMINE', Transport and Road Research Lab Contractor Report No. 28 (1986).

3. Cox, G., Kumar, S. and Markatos, N.C., 'Some field Model validation studies', Fire Safety Science - Proc. 1st International Symposium, Hemisphere (1986), p. 159

4. Kumar, S. and Cox, G., In proc. 6th International Symposium on the Aerodynamics and Ventilation of Vehicle Tunnels, BHRA (1988), p.515.

5. Kumar, S., Gupta, A.K. and Cox, G., Fire Safety Science - proceedings 3rd International Symposium (1991), p 345.

6. Shipp, M., Private communication 